\title{
Fast Determination of the Main Reduced Sulfur Species in Aquatic Systems by a Direct and Second-Derivative Spectrophotometric Method
}

\author{
Sébastien Dupraz $\mathbb{D}^{1},{ }^{1,2}$ Bénédicte Ménez, ${ }^{1}$ and François Guyot ${ }^{3}$ \\ ${ }^{1}$ Université de Paris, Institut de Physique du Globe de Paris, CNRS and Centre de Recherches sur le Stockage Géologique du CO \\ (IPGP/TOTAL/SCHLUMBERGER/ADEME), 1 Rue Jussieu, 75238 Paris Cedex 05, France \\ ${ }^{2}$ Bureau de Recherches Géologiques et Minières (BRGM), 3 Avenue Claude-Guillemin, 45060 Orléans, France \\ ${ }^{3}$ Institut de Minéralogie, de Physique des Matériaux et de Cosmochimie, Sorbonne-Université, IRD, \\ Museum National d'Histoire Naturelle, CNRS, 4 Place Jussieu, 75252 Paris Cedex 05, France \\ Correspondence should be addressed to Sébastien Dupraz; s.dupraz@brgm.fr
}

Received 13 March 2019; Accepted 10 June 2019; Published 2 July 2019

Academic Editor: Patricia E. Allegretti

Copyright (c) 2019 Sébastien Dupraz et al. This is an open access article distributed under the Creative Commons Attribution License, which permits unrestricted use, distribution, and reproduction in any medium, provided the original work is properly cited.

\begin{abstract}
The determination of reduced sulfur species in aquatic systems is not an easy and fast task to accomplish regarding the numerous possible interferences and risks of oxidation that occur with the usual methods of quantification. The method presented here is a direct spectrophotometric method that can be used to quantify sulfides, sulfites, and thiosulfates in a simple and rapid way. The principle is based on the comparison of second-derivative absorbance spectra of the same sample at different $\mathrm{pH}(9.2,4.7$, and 1.0$)$ and selected absorption wavelengths $(250$ and $278 \mathrm{~nm}$ ). This method has been successfully tested and has demonstrated liability to (i) avoid the biases due to absorbance overlaps between the different major chemical species and (ii) keep, as a direct method, the advantages over indirect methods on interferences reduction. The limits of detections (LOD) reached for total sulfide, sulfite, and thiosulfate are $1.37,7.32$, and $1.92 \mu \mathrm{M}$, respectively. The method displays low accuracy mean and low relative standard deviation $(<4 \%)$ as well as a good linearity $\left(R^{2}>0.999\right)$. Accordingly, this method represents a very robust alternative in terms of cost and rapidity for the quantification of reduced sulfur species in different aquatic environments, from freshwaters to saline and polluted systems.
\end{abstract}

\section{Introduction}

The chemistry of reduced sulfur species plays a predominant role in numerous applications and fundamental studies related to anoxic environments like, for instance, underground fluids and ecosystems of the subsurface, deep water areas, swamps, sediments, decaying organic matter, and sewers [1-4]. It is also the case in applied research dealing with anaerobic bioreactors, water purification, petrochemical plants, food processing, paper mills, and tanneries [5-8]. If we consider the chemistry of natural systems, the major soluble species for oxygenated waters is sulfates $\left(\mathrm{SO}_{4}{ }^{2-}\right)$. For anoxic media, the most predominant species are sulfides $\left(\mathrm{HS}^{-}\right.$and $\mathrm{S}^{2-}$ ) and dissolved hydrogen sulfide $\left(\mathrm{H}_{2} \mathrm{~S}\right)$, followed by thiosulfates $\left(\mathrm{HS}_{2} \mathrm{O}_{3}{ }^{-}\right.$and $\left.\mathrm{S}_{2} \mathrm{O}_{3}{ }^{2-}\right)$, polysulfides $\left(\mathrm{H}_{2} \mathrm{~S}_{x}, \mathrm{HS}_{x}^{-}\right.$, and $S_{x}^{2-}$ with $x=2$ to 9), colloidal elemental sulfur $\left(\alpha-S_{8}\right)$, and polythionates $\left(\mathrm{S}_{x} \mathrm{O}_{6}{ }^{2-}\right.$ with $x=3$ to 6) [9-11]. The other species, called intermediate sulfur species, generally represent a very small fraction $(<0.01 \%)$ of the total dissolved sulfur content [12]. Nevertheless, several studies realized in brines, volcanic lakes, and hydrothermal systems have found relative proportions of thiosulfates and polythionates, which could reach $20 \%$ of the total dissolved sulfur content $[12,13]$. Sulfites $\left(\mathrm{HSO}_{3}{ }^{-}\right.$and $\mathrm{SO}_{3}{ }^{2-}$ ) are less frequently found in natural environments because of their relatively low stability. However, they can be found at high levels in hot springs [14] and are also very commonly used in food and beverage industries as preservatives $[15,16]$.

Due to the variable relative abundance of sulfur species in the environment and their implication in numerous 
microbial metabolisms, their monitoring is frequently required to assess the nature and level of activities of anaerobic ecosystems in fundamental or applied research. Checking the presence of these species is also needed for qualitative requirements and security controls, like, for instance, rotten egg flavor and toxicity due to hydrogen sulfide presence $[17,18]$. The main techniques that are generally used for quantification are, by order of popularity [19], indirect ultraviolet (UV)/visible spectrophotometric measurements $[20,21]$, potentiometric measurements, and separation methods like ion/gas chromatography, capillary electrophoresis, and flow-based methods that can be coupled to spectrophotometry, fluorimetry, electrochemical measurements, absorption/emission atomic spectrometry, and flame photometry for volatile species [7, 22-25]. The major drawback of all these techniques is their sensitivity to water composition that require considerable instrumental, procedural, and technical needs to be implemented [26]. In particular, improvements in selectivity are still needed to allow measurements of sulfides in saline or highly polluted waters [19]. Moreover, due to the strong reactivity of the reduced sulfur species to oxygen, sample handling and preparation are tedious, while it should be as short and direct as possible. Consequently, there is a strong need for a robust method that would be simple, fast to implement, and adaptable to a broad set of waters.

Direct spectrophotometric measurements have this potential but they are generally not used because of the great number of compounds that share the same absorbance regions in the UV/visible domain. For instance, the quantification of thiosulfates, sulfides, and sulfites by spectrophotometry is hampered by the fact that these compounds absorb the UVvisible light in the same range of wavelengths. Notably, sulfides show interferences with the sulfite species, and consequently, it is only possible to determine the total sulfide content when the amount of sulfites present in the system is known beforehand. Nevertheless, improvement in these approaches has been accomplished through specific spectral deconvolution routines [27] or by the use of second-derivative absorbance quantification procedures that allow the removal of nonspecific linear absorbencies in the spectrum [28].

The method proposed here is also based on direct spectrophotometric measurements but in three different media buffered at selected $\mathrm{pH}$. Regulation by mean of $\mathrm{pH}$ is commonly used before direct spectrophotometric measurements in order to assess the absorption coefficient of a chemical species sensitive to $\mathrm{pH}$ (i.e., acid and base conjugates). With this information, it is then possible to determine, for a given aqueous solution, the concentration of this species whatever the $\mathrm{pH}$ is. On the contrary, in our method, sample measurement is directly achieved in media with selected fixed $\mathrm{pH}$ and leads to the quantification of all the acids and bases that derive from a given species. Admitting that the acid-base reactions are instantaneous, the direct measurements at adequate $\mathrm{pH}$ values can indeed take into account all the protonated and unprotonated forms of this species. In addition, a specific absorbance observed in one buffered medium may disappear totally or maintain itself constant in another buffered medium, these properties being explained by the differences between the pKa of the various targeted species. Therefore, by subtracting absorbance spectra of the same sample diluted in media with different $\mathrm{pH}$ and by choosing appropriately the characteristic wavelengths to be measured, the suppression or isolation of a given signal is possible. The absorbance overlaps coming from other sulfur species but also from the main inorganic and organic components commonly found in natural environments can similarly be removed. However, this procedure prevents the possibility of distinguishing the proportion of different acids, bases, and ampholytes that are controlled by acid-base equilibria. Nevertheless, and as previously stated, this relative distribution can be established retrospectively by knowing the sample initial $\mathrm{pH}$.

Sulfides were selected as the main target of our quantification method because, as discussed previously, they represent the main reduced sulfur species in natural systems, but they are still difficult to quantify. Thiosulfates and sulfites were also selected because they are among the most soluble species of the common reduced sulfur compounds and the main intermediate products of sulfide oxidation $[2,29]$. We present here principles and results of the calibration and interference tests, which allowed to assess method liability.

\section{Materials and Methods}

2.1. Chemicals. The method was calibrated with standard solutions containing various concentrations (up to $500 \mathrm{mM}$ ) of thiosulfate, sulfite, and sulfide species initially under the following forms: sodium thiosulfate $\left(\mathrm{Na}_{2} \mathrm{~S}_{2} \mathrm{O}_{3}\right)$ from Fisher Chemicals (volumetric solution), sodium sulfite anhydrate $\left(\mathrm{Na}_{2} \mathrm{SO}_{3}\right)$ from Fisher Chemicals (Laboratory Reagent Grade), and sodium sulfide nanohydrate $\left(\mathrm{Na}_{2} \mathrm{~S} \cdot 9 \mathrm{H}_{2} \mathrm{O}\right)$ from Fluka (32-38\%). All the solutions were prepared with deaerated ultrapure water (UPW; reverse osmosis system PURELAB ${ }^{\circledR}$ Prima from ELGA, with a resistivity of $18 \mathrm{M} \Omega \cdot \mathrm{cm}$ ) and stored under argon atmosphere. Solutions were also amended with $\mathrm{NaCl}$ or $\mathrm{NO}_{3}{ }^{-}$in order to test the impact of salinity and high nitrate levels on the method liability. Yeast extracts (Hy-Yest ${ }^{\circledR}$ 412, SigmaAldrich) and humic acids (purified humic acid technical grade solution from Sigma-Aldrich) were also used to mimic naturally occurring organic matter and assess potential interferences on the method. With the exception of these latter organic substances, all the other chemicals used were of NORMAPUR ${ }^{\circledR}$ quality or certified to meet the American Chemical Society specifications for analysis.

2.2. Spectrophotometric Measurements. All the measurements were performed in Herasil quartz cuvettes (HELLMA ${ }^{\circledR} \mathrm{N} 6040,10 \mathrm{~mm}$ in length) inserted in a UV/ visible Shimadzu double-beam spectrophotometer (UV1650PC, deuterium lamp). The UVProbe software (Shimadzu) was used for data acquisition and processing.

2.3. General Protocol. A schematic description of the protocol is given in Figure 1. Samples and aliquots of the standard solutions were filtered with Millipore filters $(0.2 \mu \mathrm{m}$ 


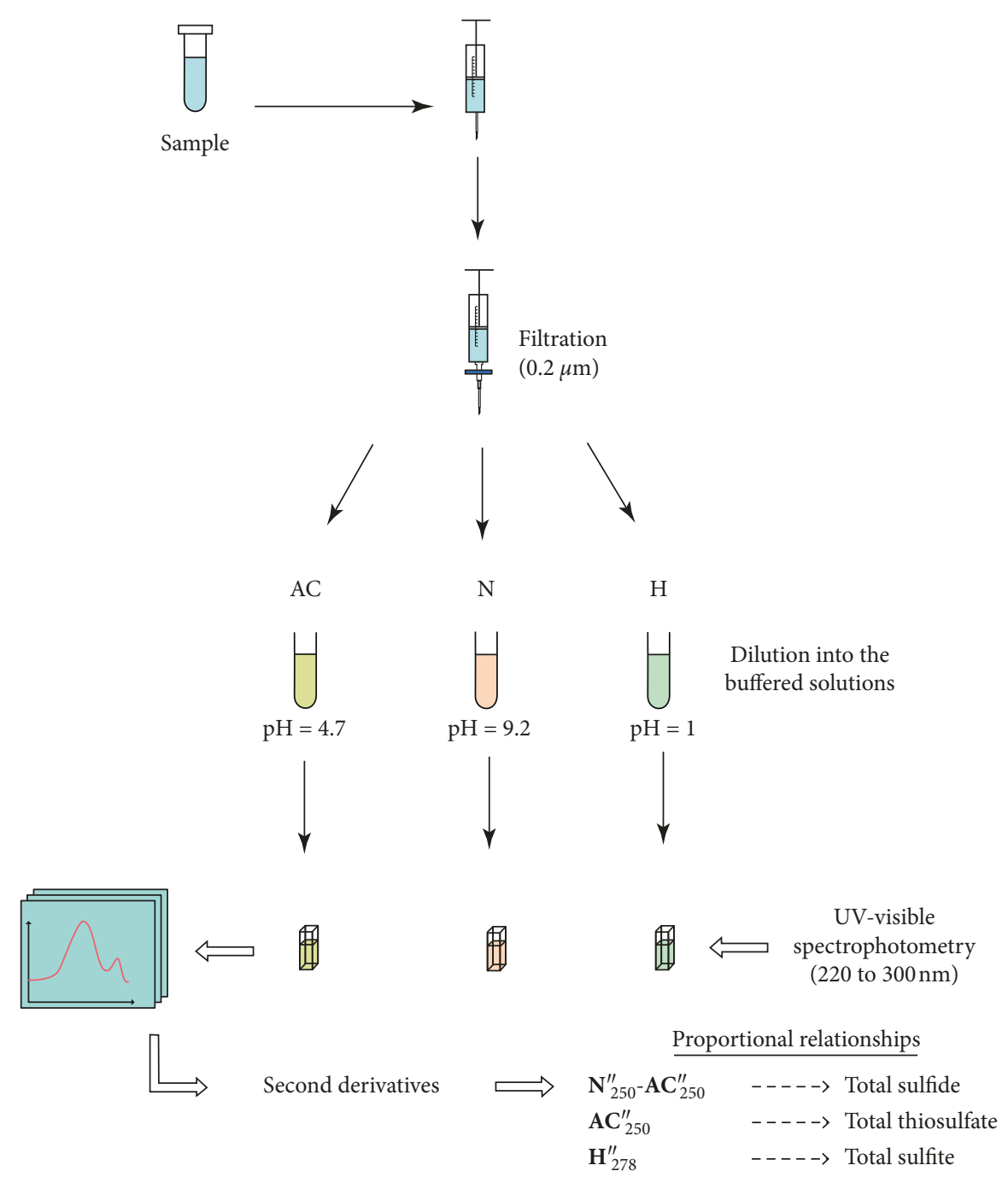

Figure 1: Schematic representation of the quantification procedure proposed in this study. From a filtered sample, three direct spectrophotometric spectra are acquired in three different buffered media $(\mathbf{N}, \mathrm{pH}=9.2 ; \mathbf{A C}, \mathrm{pH}=4.7 ;$ and $\mathbf{H}, \mathrm{pH}=1.0)$ in the range $220-300 \mathrm{~nm}$. Spectra are differentiated to the second degree $\left(\mathbf{N}^{\prime \prime}, \mathbf{A} \mathbf{C}^{\prime \prime}\right.$, and $\left.\mathbf{H}^{\prime \prime}\right)$, and values of second derivative absorbance are extracted at specific wavelengths $\left(\mathbf{N}_{\mathbf{2 5 0}}^{\prime \prime}, \mathbf{A C}_{\mathbf{2 5 0}}^{\prime \prime}\right.$ at $250 \mathrm{~nm}$, and $\mathbf{H}_{278}^{\prime \prime}$ at $\left.278 \mathrm{~nm}\right)$. These values can be used to directly quantify total thiosulfate $\left(\mathrm{H}_{2} \mathrm{~S}_{2} \mathrm{O}_{3} / \mathrm{HS}_{2} \mathrm{O}_{3}{ }^{-} /\right.$ $\left.\mathrm{S}_{2} \mathrm{O}_{3}{ }^{2-}\right)$ and sulfite $\left(\mathrm{SO}_{2} / \mathrm{HSO}_{3}{ }^{-} / \mathrm{SO}_{3}{ }^{2-}\right)$ contents, or, after subtraction, total sulfide concentration $\left(\mathrm{H}_{2} \mathrm{~S} / \mathrm{HS}^{-} / \mathrm{S}^{2-}\right)$.

ISOPORE $\left.^{\mathrm{TM}}\right)$ and directly added to three different $\mathrm{pH}$ buffered media of decreasing $\mathrm{pH}(\mathbf{N}, \mathbf{A C}$, and $\mathbf{H}$ media, respectively) with (i) $\mathrm{N}$ corresponding to $\mathrm{NH}_{3}(\cong 6.25 \mathrm{mmol} /$ $\mathrm{L}$ or $4 \mu \mathrm{L} / \mathrm{L}$ from a $25-30 \% \mathrm{NH}_{3}$ solution) mixed with $\mathrm{NH}_{4} \mathrm{Cl}$ $(6.25 \mathrm{mmol} / \mathrm{L})$, leading to a final $\mathrm{pH}$ of 9.2 , (ii) AC corresponding to a mix of Na-acetate trihydrate $(6.25 \mathrm{mmol} / \mathrm{L})$ and acetic acid $(6.25 \mathrm{mmol} / \mathrm{L})$ with a final $\mathrm{pH}$ of 4.7 , and (iii) $\mathrm{H}$ corresponding to $\mathrm{HCl}$ at $0.1 \mathrm{~mol} / \mathrm{L}$ with an associated $\mathrm{pH}$ of 1 . All these media were prepared in UPW and formulated in order to reach a final volume of $10 \mathrm{~mL}$ after sample addition. Variations in the injected volume of sample in this formulation allowed different dilutions.

Spectra were recorded for each medium right after sample addition using the following parameters: spectral acquisition between 220 and $300 \mathrm{~nm}$, wavelength scanning speed (slow, $\cong 32 \mathrm{~nm} / \mathrm{min}$ ), single acquisition, and data bunching interval of $0.1 \mathrm{~nm}$. If not specified, the blanks associated with these measurements were made with the same buffered medium ( $\mathbf{N}, \mathbf{A C}$, or $\mathbf{H})$, without any addition of the sample. Acquisitions were performed at controlled room temperature $\left(25^{\circ} \mathrm{C}\right)$ with thermally equilibrated solutions.

2.4. UV-Visible Spectrophotometric Characterization of the Buffered Media. The UV-visible spectral signature of each medium ( $\mathbf{N}, \mathbf{A C}$, and $\mathbf{H}$ ) was established by a series of 10 measurements. For these acquisitions, blanks consisted in UPW. The pH stability of the media was frequently checked, and care was taken to not let the recipients open to the atmosphere in order to avoid changes in the neutral species (i.e., $\mathrm{NH}_{3}$ and acetic acid) due to air-solution exchanges.

2.5. Calibration Curves. Each of the three species of interest (sulfides, sulfites, and thiosulfates) was analyzed three times in each media (made independently for each measurements) 
at a concentration of $0.5 \mathrm{mmol} / \mathrm{L}$ (or $0.25 \mathrm{mmol} / \mathrm{L}$ for sulfides in medium N). Each measurement was repeated two times (gap of $3 \mathrm{~min}$ between the onset of each measurement) in the same cuvette in order to detect and quantify any temporal modification of the signal (e.g., oxidation by air dioxygen). The individual calibration lines for each species were then obtained by measuring 5 different dilutions with final concentrations ranging from 500 to $4 \mu \mathrm{mol} / \mathrm{L}$.

2.6. Interferences Tests. Tests for specific interferences were conducted by first mixing the three sulfur species (sulfides, sulfites, and thiosulfates) at $100 \mu \mathrm{mol} / \mathrm{L}$ each, with solution at different salinities $(100,14.6,7.3,3.65$, and $0 \mathrm{~g} / \mathrm{L}$ of $\mathrm{NaCl})$ in order to estimate the impact of ionic strength increase on the signal stability, then with a synthetic seawater (i.e., TYA medium described in [30]) diluted 10 and 40 times in order to mimic general ionic background of saline and marine waters and finally with $10 \mathrm{mg} / \mathrm{L}$ of humic acid because it represents the main organic constituent of surface aquatic systems. Additionally, UV-visible spectra were also acquired on nitrate-, $\mathrm{NaCl}-$, and humic acid solutions and on the TYA medium separately mixed with each of the three media $(\mathbf{N}, \mathbf{A C}$, and $\mathbf{H})$. Tests were also performed with yeast extract because it provides a large diversity of organic compounds (e.g., proteins, amino acids, and carbohydrates) that are frequently found associated with animal and microbial water pollution. All these measurements were, at least, triplicated. Interference threshold values were defined as the concentration that gives a signal variation equal to the corresponding smallest limit of detection (see below). In parallel, a linearity comparison test was also accomplished with the spectrophotometric methylene blue method (SPECTROQUANT ${ }^{\circledR}$ test kit $\mathrm{N}^{\circ}$ 1.147779.0001, Merck) using natural freshwaters spiked with sulfides. Finally, measurements were also performed on a groundwater sample exhibiting natural occurrences of sulfides, sulfites, and thiosulfates and collected in the Dogger formation of the Paris basin (Orléans, France). In order to validate the present approach, the same groundwater sample was controlled with standardized methods. Sulfur was measured using the methylene blue coloring method (ISO 10530: 1992). Sulfites were measured using the iodometric titration method (SANDRE 296), and thiosulfates were quantified with an ion-exchange chromatography protocol on ICS-3000 (ISO 10304-E).

2.7. Data Treatment and Statistical Approach. All the spectra were processed using the UVProbe software second-derivative function, which can be described by equation (1) from [31]:

$$
\frac{d^{2} A}{d \lambda^{2}}=\frac{A\left(\lambda^{\prime}+\Delta \lambda\right)-2 A\left(\lambda^{\prime}\right)+A\left(\lambda^{\prime}-\Delta \lambda\right)}{(\Delta \lambda)^{2}},
$$

where $A$ is the absorbance at a given wavelength $\lambda, \lambda^{\prime}$ is the wavelength at which the second-derivative absorbance value is calculated, and $\Delta \lambda$ is the wavelength interval. In this study, $\Delta \lambda$ was fixed at $8 \mathrm{~nm}$ in order to reduce the narrowband noise effect $[28,32]$. Second-derivative spectra from media $\mathbf{N}, \mathbf{A C}$, and $\mathbf{H}$ were named $\mathbf{N}^{\prime \prime}, \mathbf{A C}^{\prime \prime}$, and $\mathbf{H}^{\prime \prime}$, respectively.

Spectra subtractions were also performed with the UVProbe software. Calibration lines were calculated using the standard linear least square method from MICROSOFT ${ }^{\circledR}$ EXCEL.

In this study, the limit of detection (LOD) and the limit of quantification (LOQ) correspond to $3 \sigma$ and $10 \sigma$, respectively, with $\sigma$ representing the standard deviation of the blanks:

$$
\sigma=\sqrt{\frac{1}{N} \times \sum_{i=1}^{N}\left(x_{i}-\bar{x}\right)^{2}},
$$

where $N$ is the total number of measurements $i$ and $\bar{x}$ the mean of the measurement values $x$.

Accuracy was determined by

$$
\text { Accuracy }=\frac{1}{N^{\prime}} \times \sum_{i=1}^{N^{\prime}}\left(\frac{m_{i}-r_{i}}{r_{i}}\right) \times 100,
$$

where $N^{\prime}$ is the number of measurements $i$ to which corresponds a real $\left(r_{i}\right)$ and a measured $\left(m_{i}\right)$ absolute values. Only values from the calibration test higher than the LOQ were considered.

Precision was assessed using the relative standard deviation (RSD) defined in

$$
\mathrm{RSD}=\frac{1}{N^{\prime \prime}} \times \sum_{i=1}^{N^{\prime \prime}}\left(\frac{\sigma_{i}}{\bar{x}_{i}}\right) \times 100,
$$

where $N^{\prime \prime}$ is the number of measurements sets $i$ for each dilution during the calibration test. Note that only dilutions that led to measured values higher than the LOQ were considered.

\section{Results and Discussion}

3.1. Reduced S Species Distribution in pH-Buffered Media. By mixing a sample containing sulfides with the three $\mathrm{pH}$ buffered media $\mathbf{N}, \mathbf{A C}$, and $\mathbf{H}$ at $\mathrm{pH}$ of 9.2, 4.7, and 1, respectively, we will form more than $99 \%$ of $\mathrm{HS}^{-}$in $\mathbf{N}$ and more than $99 \%$ of $\mathrm{H}_{2} \mathrm{~S}$ in $\mathbf{A C}$ and $\mathbf{H}$, according to the pKa of this species (Table 1). Second-derivative absorbance spectra acquired for the three different media (i.e., $\mathbf{N}^{\prime \prime}, \mathbf{A \mathbf { C } ^ { \prime \prime }}$, and $\mathbf{H}^{\prime \prime}$ ) show a maximum at a wavelength of $250 \mathrm{~nm}$ only for $\mathrm{HS}^{-}$ (i.e., $\mathbf{N}^{\prime \prime}$ ), whereas $\mathrm{H}_{2} \mathrm{~S}$ displays no specific signal in $\mathbf{A \mathbf { C } ^ { \prime \prime }}$ and $\mathbf{H}^{\prime \prime}$ (Figure 2(a)). Similarly, for sulfites, media $\mathbf{N}$ and $\mathbf{A C}$ will contain more than $99 \%$ of $\mathrm{SO}_{3}{ }^{2-}$ and $\mathrm{HSO}_{3}{ }^{-}$respectively, while medium $\mathrm{H}$ will consist of about $86 \%$ of $\mathrm{SO}_{2}$ and $14 \%$ of $\mathrm{HSO}_{3}{ }^{-}$. Second-derivative spectrum $\mathbf{H}^{\prime \prime}$ acquired in this last medium presents a minimum for $\mathrm{SO}_{2}$ at $278 \mathrm{~nm}$ (Figure 2(b)). The signal for the $\mathrm{SO}_{3}{ }^{2-}$ and $\mathrm{HSO}_{3}{ }^{-}$mixture is not discriminant. At last, for $\mathrm{pH}$ higher than 1.7, thiosulfates will be present as $\mathrm{S}_{2} \mathrm{O}_{3}{ }^{2-}$. Second-derivative spectra $\mathrm{N}^{\prime \prime}$ and $\mathbf{A C}^{\prime \prime}$ display in accordance the same signal intensity for $\mathrm{S}_{2} \mathrm{O}_{3}{ }^{2-}$ with a maximum in absorbance at $244 \mathrm{~nm}$ (Figure 2(c)), while $\mathbf{H}^{\prime \prime}$ corresponds to a combination 
TABLE 1: pKa of frequently encountered sulfur species (in water at $\left.25^{\circ} \mathrm{C}\right)$.

\begin{tabular}{lcc}
\hline Acids/Bases & $\mathrm{pKa}(\mathrm{s})$ & References \\
\hline $\mathrm{H}_{2} \mathrm{~S} / \mathrm{HS}^{-} / \mathrm{S}^{2-}$ & $7.0 / 12.9$ & {$[33]$} \\
$\mathrm{H}_{2} \mathrm{~S}_{2} / \mathrm{HS}_{2}{ }^{-} / \mathrm{S}_{2}{ }^{2-}$ & $5.0 / 9.7$ & {$[34]$} \\
$\mathrm{H}_{2} \mathrm{~S}_{3} / \mathrm{HS}_{3}{ }^{-} / \mathrm{S}_{3}{ }^{2-}$ & $4.2 / 7.5$ & {$[34]$} \\
$\mathrm{H}_{2} \mathrm{~S}_{4} / \mathrm{HS}^{4-} / \mathrm{S}_{4}{ }^{2-}$ & $3.8 / 6.3$ & {$[34]$} \\
$\mathrm{H}_{2} \mathrm{~S}_{5} / \mathrm{HS}^{5-} / \mathrm{S}_{5}{ }^{2-}$ & $3.5 / 5.7$ & {$[34]$} \\
$\mathrm{H}_{2} \mathrm{~S}_{2} \mathrm{O}_{3} / \mathrm{HS}_{2} \mathrm{O}_{3}{ }^{-} / \mathrm{S}_{2} \mathrm{O}_{3}{ }^{2-}$ & $0.6 / 1.7$ & {$[35]$} \\
$\mathrm{H}_{2} \mathrm{SO}_{5} / \mathrm{HSO}_{5}{ }^{-} / \mathrm{SO}_{5}{ }^{2-}$ & $<0 / 9.3$ & {$[36]$} \\
$\mathrm{H}_{2} \mathrm{~S}_{\mathrm{x}} \mathrm{O}_{6} / \mathrm{HS}_{x} \mathrm{O}_{6}{ }^{-} / \mathrm{S}_{x} \mathrm{O}_{6}{ }^{2-}(x=3-5)$ & $? /-2.3$ & {$[37]$} \\
$\mathrm{H}_{2} \mathrm{SO}_{3} / \mathrm{HSO}_{3}{ }^{-} / \mathrm{SO}_{3}{ }^{2-}$ & $1.8 / 7.2$ & {$[38,39]$} \\
$\mathrm{H}_{2} \mathrm{SO}_{4} / \mathrm{HSO}_{4}{ }^{-} / \mathrm{SO}_{4}{ }^{2-}$ & $-3.0 / 2.0$ & {$[40,41]$} \\
$\mathrm{HSCN} \mathrm{SCN}^{-}$ & 1.3 & {$[42]$} \\
$\mathrm{S}_{2} \mathrm{O}_{4} \mathrm{H}_{2} / \mathrm{S}_{2} \mathrm{O}_{4} \mathrm{H}^{-} / \mathrm{S}_{2} \mathrm{O}_{4}{ }^{2-}$ & $0.3 / 2.4$ & {$[33]$} \\
\hline
\end{tabular}

between the $\mathrm{HS}_{2} \mathrm{O}_{3}{ }^{-}$and $\mathrm{S}_{2} \mathrm{O}_{3}{ }^{2-}$ absorbance (estimated proportion is $60 / 40 \%)$.

3.2. Method of Quantification. When sulfites, sulfides, and thiosulfates are mixed together, if one wants to isolate the sulfide characteristic signal at $250 \mathrm{~nm}\left(\mathbf{N}_{250}^{\prime \prime}\right)$ from those of thiosulfates and sulfites, the best option is to subtract the second-derivative spectrum $\mathbf{A C}$ " from the second-derivative spectrum N". Proceeding this way, the contribution of thiosulfates, which is strictly the same in these two secondderivative spectra, is thus cancelled. The sulfides are not

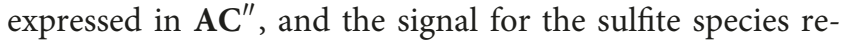
mains low at the wavelength of $250 \mathrm{~nm}$ for both $\mathbf{N}^{\prime \prime}$ and $\mathbf{A C}^{\prime \prime}$ $\mathrm{pH}$ even if the difference between the two second-derivative spectra is non-negligible (Figures 2(a) and 2(b)). For sulfite quantification, the second-derivative absorbance value at $278 \mathrm{~nm}$ and $\mathrm{pH}=1\left(\mathbf{H}_{278}^{\prime \prime}\right)$ can be directly read on spectra, since sulfides and thiosulfates do not interfere at these wavelength and $\mathrm{pH}$ (Figure 2). In the same way, thiosulfates can also be directly measured at $243 \mathrm{~nm}$ at $\mathrm{pH}$ of 4.7 since there is no significant contribution of sulfides and sulfites in AC buffered medium (Figures 2(a) and 2(b)). Despite the fact that the maximum of the second-derivative absorbance appears at $244 \mathrm{~nm}$ for thiosulfates (Figure 2(c)), the value at $250 \mathrm{~nm}$ was preferred $\left(\mathbf{A C}_{\mathbf{2 5 0}}^{\prime \prime}\right)$, because the sulfite signal starts to be significant below $250 \mathrm{~nm}$ at this $\mathrm{pH}$ (Figure 2(b)).

One of the major hindrances for ionic quantifications by spectrophotometry is sample salinity. In brines analysis, this implies dilution steps or strong matrix effects during measurements [43-45]. The present method was tested for salinities ranging from 0 to $100 \mathrm{~g} / \mathrm{L}$. Results display linear trends for the normalized second-derivative absorbance of the three sulfur species (Figure 3). Surprisingly, the sulfide signal is not significantly affected, and their quantification remains unchanged when salinity increases. For sulfites and thiosulfates, the normalized second-derivative absorbance is, respectively, increased up to $80 \%$ or understated by $30 \%$ at the highest tested salinity (i.e., $100 \mathrm{~g} / \mathrm{L}$ ), and linear correction is thus mandatory. Knowing that the solubility limit of $\mathrm{NaCl}$ in water at $25^{\circ} \mathrm{C}$ is close to $317 \mathrm{~g} / \mathrm{L}$ [46], a $4 \times$ dilution would reduce all samples salinities below $100 \mathrm{~g} / \mathrm{L}$ and thus allows performing a linear correction for sulfites and thiosulfates in every case.

Calibration curves for each sulfur species were obtained for various dilutions leading to final concentrations ranging from 0 to $250 \mathrm{mM}$ for total sulfide and 0 to $500 \mathrm{mM}$ for total sulfite and thiosulfate (Figure 4). They all show a good linearity according to the dose (with $R^{2}$ values ranging from 0.9992 to 0.9998 ). Coefficients of secondderivative absorbances $\boldsymbol{\alpha}, \boldsymbol{\beta}$, and $\boldsymbol{\gamma}$ (for sulfides, sulfites, and thiosulfates, respectively) were deduced from these calibration curves by a least squares regression. A fourth coefficient $(\boldsymbol{\delta})$ was also evaluated in order to provide a correction for sulfide measurements regarding sulfite interferences:

$$
\begin{aligned}
\boldsymbol{\alpha}\left(\text { sulfides, } \mathbf{N}_{\mathbf{2 5 0}}^{\prime \prime}-\mathbf{A C}_{\mathbf{2 5 0}}^{\prime \prime}\right) & =23.89 \times 10^{-3} \mathrm{~L} / \mathrm{mmol} / \mathrm{cm}, \\
\boldsymbol{\beta}\left(\text { sulfites, } \mathbf{H}_{250}^{\prime \prime}\right) & =-1.480 \times 10^{-3} \mathrm{~L} / \mathrm{mmol} / \mathrm{cm}, \\
\gamma\left(\text { thiosulfates, } \mathbf{A C}_{250}^{\prime \prime}\right) & =4.635 \times 10^{-3} \mathrm{~L} / \mathrm{mmol} / \mathrm{cm}, \\
\boldsymbol{\delta}\left(\text { sulfites, } \mathbf{N}_{\mathbf{2 5 0}}^{\prime \prime}-\mathbf{A C}_{250}^{\prime \prime}\right) & =0.8627 \times 10^{-3} \mathrm{~L} / \mathrm{mmol} / \mathrm{cm} .
\end{aligned}
$$

Once the different coefficients of second-derivative absorbance are defined, with the help of the equations of the corresponding linear regressions, it is possible to establish formulas taking into account the different corrections that are required. These corrections correspond to the subtraction of the sulfite contribution to the sulfide quantification and the linear correction for salinity, which is mandatory for sulfite and thiosulfate quantification (with linear regression shown in Figure 3). Those quantification equations are described hereafter (Equations (6) to (8)), where concentrations are in $\mathrm{mmol} / \mathrm{L}$ and salinity (S) is in $\mathrm{g} / \mathrm{L}$ :

$$
\text { [sulfides }]=\frac{\left(\mathbf{N}_{\mathbf{2 5 0}}^{\prime \prime}-\mathbf{A C}_{\mathbf{2 5 0}}^{\prime \prime}\right)+0.9389 \times 10^{-5}-[\text { sulfites }] \times \boldsymbol{\delta}}{\boldsymbol{\alpha}},
$$

$$
\begin{aligned}
& {\left[\text { sulfites] }=\frac{\mathbf{H}_{278}^{\prime \prime}-0.2748 \times 10^{-5}}{(1+S \times 0.0074) \times \boldsymbol{\beta}},\right.} \\
& {\left[\text { thiosulfates] }=\frac{\mathbf{A C}_{250}^{\prime \prime}-2.098 \times 10^{-5}}{(1-S \times 0.0026) \times \gamma} .\right.}
\end{aligned}
$$

3.3. Potential Interferences. Other reduced sulfur species may also interfere in such kind of approach. Above $\mathrm{pH}=7$, colloidal sulfur rings, which represent the dominant form of elemental sulfur in polar solvents and are the precursor of common orthorhombic sulfur crystals [46], tend to form yellow-orange solutions of polysulfides by association with HS $^{-}$. Those polymers have an average size of about 5 sulfur atoms. They absorb in the UV-bc range and could be quantified as $S^{\circ}$ in $S_{x}{ }^{2-}$ by direct measurement at $285 \mathrm{~nm}$ for pHs between 8 and 10 with an average molar extinction coefficient of $1370.10^{-3} \mathrm{~L} / \mathrm{mmol} / \mathrm{cm}[47,48]$. Nevertheless, the kinetics of formation and decomposition at room 

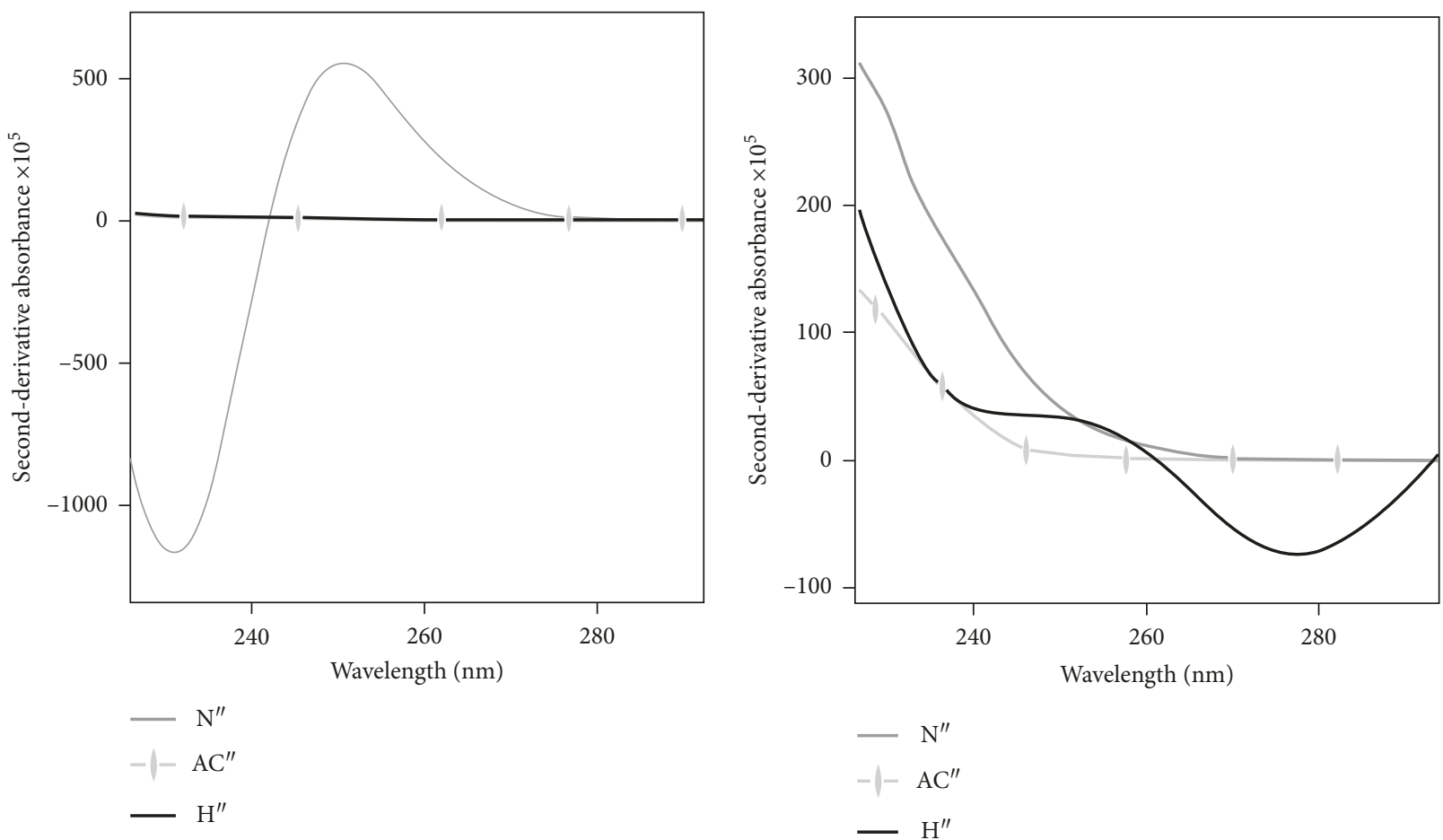

(a)

(b)

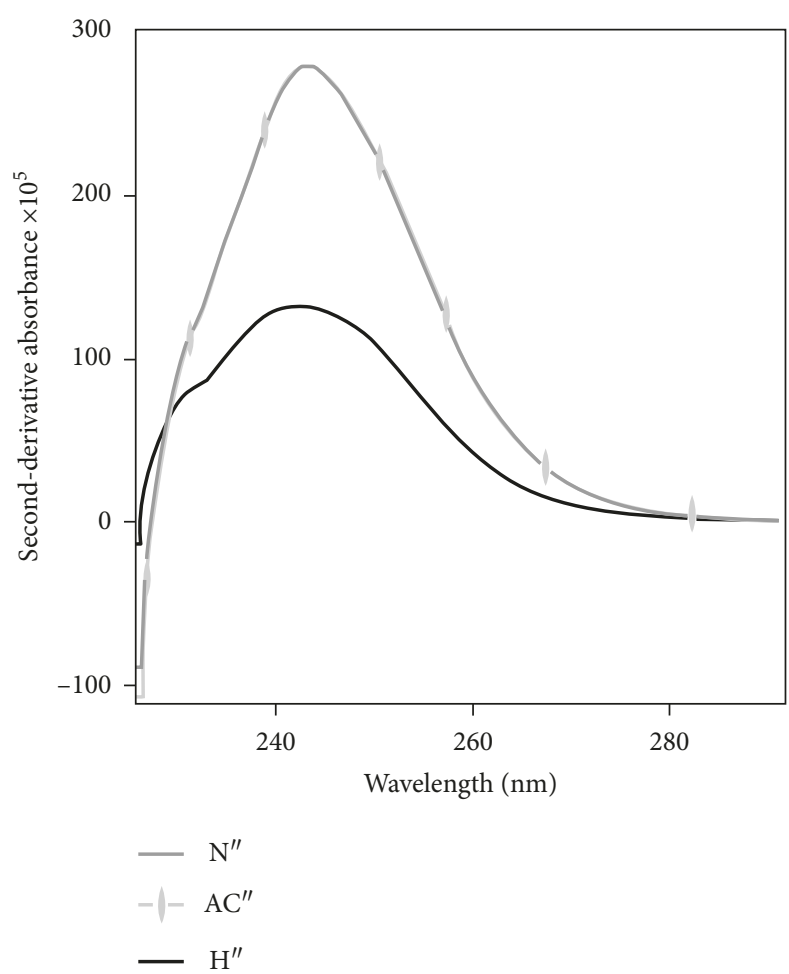

(c)

Figure 2: Second-derivative absorbance spectra ( $\mathbf{N}^{\prime \prime}, \mathbf{A C}$, and $\left.\mathbf{H}^{\prime \prime}\right)$ for (a) sulfides $\left(\mathrm{Na}_{2} \mathrm{~S}\right.$ solution at $\left.235 \mu \mathrm{mol} / \mathrm{L}\right)$, (b) sulfites $\left(\mathrm{Na}_{2} \mathrm{SO}\right.$ solution at $490 \mu \mathrm{mol} / \mathrm{L})$, and (c) thiosulfates $\left(\mathrm{Na}_{2} \mathrm{~S}_{2} \mathrm{O}_{3}\right.$ solution at $\left.500 \mu \mathrm{mol} / \mathrm{L}\right)$ between 220 and $300 \mathrm{~nm}$ at $25^{\circ} \mathrm{C}$ in three different buffered media $(\mathbf{H}, \mathrm{pH}=1.0 ; \mathbf{A C}, \mathrm{pH}=4.7$; and $\mathbf{N}, \mathrm{pH}=9.2)$. Note that $\mathbf{H}^{\prime \prime}$ and $\mathbf{A} \mathbf{C}^{\prime \prime}$ spectra merge in (a) while $\mathbf{N}^{\prime \prime}$ and $\mathbf{A C} \mathbf{C}^{\prime \prime}$ are superposed in (c). Sulfides display a maximum at $250 \mathrm{~nm}$ for a $\mathrm{pH}$ of $9.2\left(\mathbf{N}^{\prime \prime}\right)$, while a minimum is reached for sulfites at $278 \mathrm{~nm}$ for a $\mathrm{pH}$ of $1\left(\mathbf{H}^{\prime \prime}\right)$. For thiosulfates, maxima are found at $244 \mathrm{~nm}$ for the three media $\left(\mathbf{N}^{\prime \prime}, \mathbf{H}^{\prime \prime}\right.$, and $\left.\mathbf{A C}^{\prime \prime}\right)$. Optical path length and $\Delta \lambda$ were of $10 \mathrm{~mm}$ and $8 \mathrm{~nm}$, respectively. 


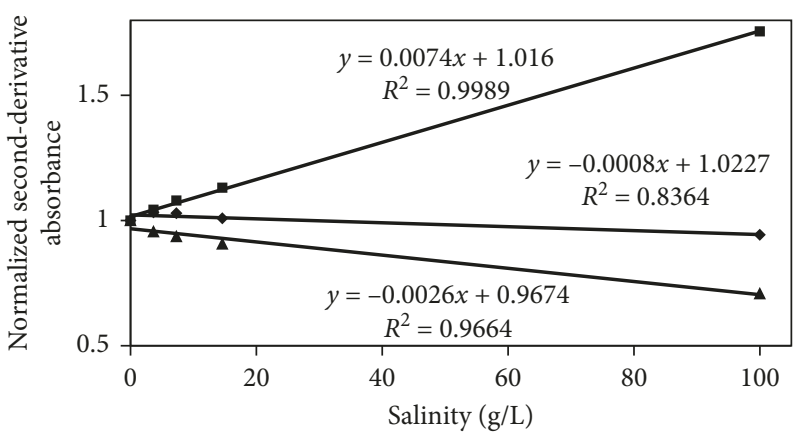

FIGURE 3: Normalized second-derivative absorbance as a function of salinity: values for $\mathbf{N}_{\mathbf{2 5 0}}^{\prime \prime}-\mathbf{A C}_{\mathbf{2 5 0}}^{\prime \prime}$ (second-derivative values at $250 \mathrm{~nm}$ for media ( $\mathbf{N}$ and $\mathbf{A C}$, respectively)) are represented by diamonds and correspond to total sulfide $\left(\mathrm{H}_{2} \mathrm{~S} / \mathrm{HS}^{-} / \mathrm{S}^{2-}\right)$. Values $\mathbf{H}_{278}^{\prime \prime}(\mathrm{second}-$ derivative values at $278 \mathrm{~nm}$ for media $\mathbf{H}$ and representing total sulfite: $\mathrm{SO}_{2} / \mathrm{HSO}_{3}{ }^{-} / \mathrm{SO}_{3}{ }^{2-}$ ) and $\mathbf{A C}_{250}^{\prime \prime}$ (second-derivative values at $250 \mathrm{~nm}$ for media $\mathrm{AC}$ and representing total thiosulfate: $\mathrm{H}_{2} \mathrm{~S}_{2} \mathrm{O}_{3} / \mathrm{HS}_{2} \mathrm{O}_{3}{ }^{-} / \mathrm{S}_{2} \mathrm{O}_{3}{ }^{2-}$ ) are represented by squares and triangles, respectively.

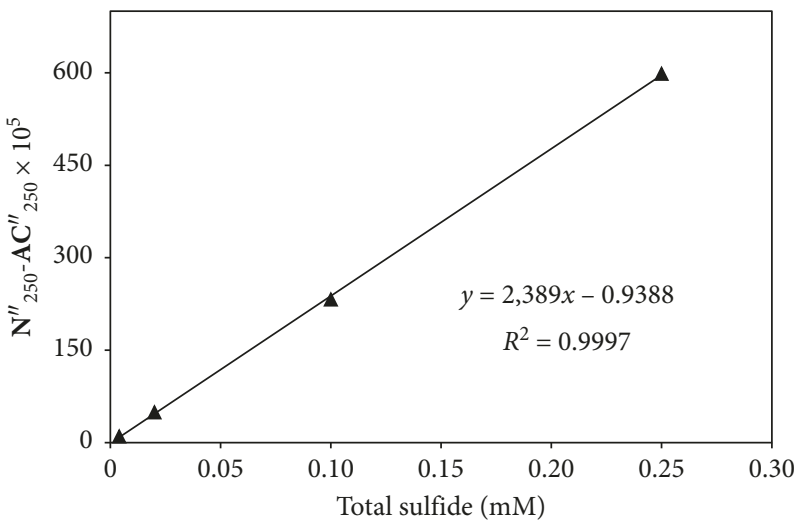

(a)

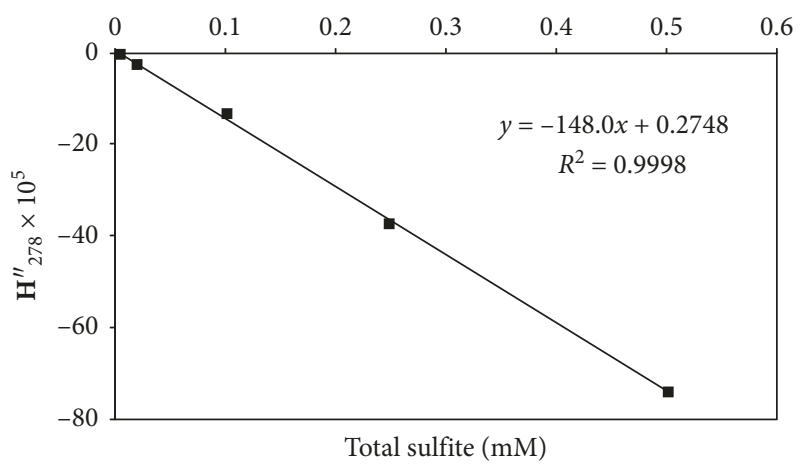

(b)

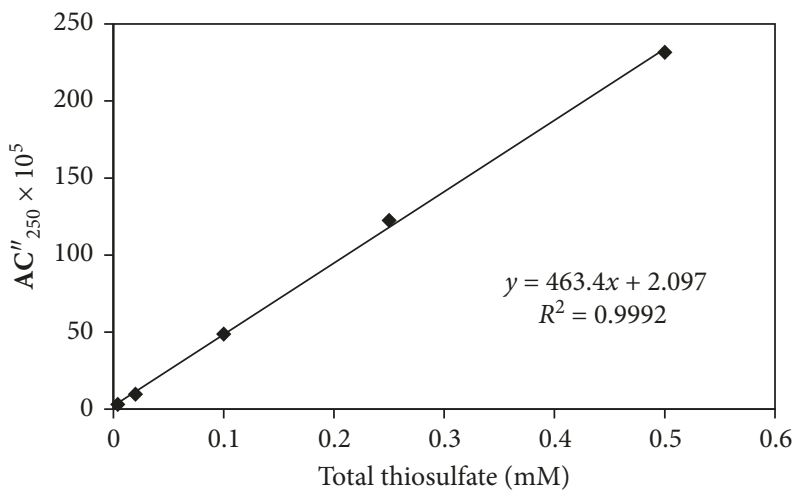

(c)

FIGURE 4: Calibration curves of the second-derivative absorbance parameters for total sulfide (a), total sulfite (b), and total thiosulfate (c) in water at $25^{\circ} \mathrm{C}$.

temperature are not fast enough to significantly interfere in time with a spectrophotometric measurement [49]. Similar statement can be made for polysulfanes $\left(\mathrm{H}_{2} \mathrm{~S}_{x}\right)$, which are additionally quite insoluble [50]. Consequently, no newly formed polysulfides, sulfides, or $\mathrm{S}^{\circ}$ should occur during the measurement preparation. Additionally, the contribution of the original polysulfides to sulfide quantification is cancelled anyway by the second-derivative spectra subtraction associated with our method. To the contrary, quantifications of thiosulfates and sulfites might be hampered by the presence of original polysulfides.
Polythionates (i.e., polythiosulfates) display also a strong absorbance in the UV-c range (with a maximum around $215 \mathrm{~nm}$ ) and have a spectral pattern similar to thiosulfates with the exception of trithionate that does not absorb light between 220 and $300 \mathrm{~nm}$ [23]. These species can be found in acidic hot springs, leach solutions, and volcano lakes where the dominant species are the tetrathionate followed by the penta- and trithionate [12]. Even if these species may slightly contribute to thiosulfate estimates, their concentrations are usually very low compared to thiosulfate content, and thus this should not induce significant modification of the 
thiosulfate signal in most cases. In addition to those species, dithionite $\left(\mathrm{S}_{4} \mathrm{O}_{6}{ }^{2-}\right)$, thiocyanate $\left(\mathrm{SCN}^{-}\right)$, and thiols (i.e., mercaptans) are frequently referred as being the major sources of selectivity limitation for the quantification of sulfides [19]. Nevertheless, mercaptans are generally deprotonated for $\mathrm{pH}$ values higher than 10. In addition, their protonated sulfhydryl function does not display any significant absorbance [51]. Concerning thiocyanate and dithionite, they are both deprotonated for $\mathrm{pH}$ equal to or higher than 4.7 (i.e., media $\mathbf{N}$ and $\mathbf{A C}$ in which sulfides are estimated). Moreover, thiocyanate does not show significant absorbance above $240 \mathrm{~nm}$ [52, 53]. Consequently, only sulfite and thiosulfate measurements are possibly affected by dithionite. It should also be added that the occurrence of dithionite is not natural and that this molecule is unstable in aqueous media.

If we exclude the previously mentioned reduced sulfur species, the major soluble ions, which can be found in natural waters $\left(\mathrm{H}^{+}, \mathrm{OH}^{-}, \mathrm{Cl}^{-}, \mathrm{Na}^{+}, \mathrm{Ca}^{2+}, \mathrm{Mg}^{2+}, \mathrm{K}^{+}, \mathrm{SO}_{4}{ }^{2-}\right.$, $\mathrm{HCO}_{3}{ }^{-}, \mathrm{CO}_{3}{ }^{2-}, \mathrm{BO}_{3}{ }^{3-}, \mathrm{NH}_{4}{ }^{+}, \mathrm{Sr}^{2+}$, and $\mathrm{F}^{-}$), are optically inactive between 220 and $300 \mathrm{~nm}$ [54-57]. $\mathrm{I}^{-}$and $\mathrm{NO}_{2}{ }^{-}$are absorbents but are generally found at very low concentrations. Only $\mathrm{Br}^{-}, \mathrm{NO}_{3}{ }^{-}$, and $\mathrm{Fe}^{2+}$ may cause interferences with sulfites and thiosulfates. However, as $\mathrm{HBr}$ and $\mathrm{HNO}_{3}$ are strong acids and thus always deprotonated in aquatic systems, their contributions are cancelled by the secondderivative spectra subtraction inherent to the sulfide quantification step. $\mathrm{Fe}^{2+}$ is present in numerous reduced and anoxic waters, and it absorbs in the UV range [58]. Nevertheless, as it quickly reacts with sulfides to form iron sulfides, its presence as dissolved cation is incompatible with the presence of sulfides [59]. Common dissolved inorganic gases $\left(\mathrm{CO}_{2}, \mathrm{~N}_{2}, \mathrm{CH}_{4}, \mathrm{NH}_{3}, \mathrm{H}_{2}\right.$, and noble gas) do not absorb significantly in the $200-330 \mathrm{~nm}$ range, except for $\mathrm{O}_{2}$ that can be detected below $250 \mathrm{~nm}$ at high levels [56]. Its occurrence is however not compatible with the presence of reduced sulfur species. Similarly, carbohydrates and polysaccharides, orthosilicic acid $\left(\mathrm{H}_{4} \mathrm{SiO}_{4}\right)$, aliphatic esters, ethers, alcohols, and small common organic acids (e.g., acetic acid and lactic acid) and their corresponding bases do not absorb in that domain either [51, 60, 61]. On the opposite, humic and fulvic acids, proteins, and amino acids show generally a strong absorbance in this area. Free acids and hydrolysable combined amino acids do represent the major part of dissolved nitrogen-bearing organic matter in natural waters [62]. The main optical contribution of these chemical species in the UV range arises from their content in aromatic amino acids, namely, the amount of tryptophan and tyrosine [63]. Nevertheless, the second derivatization of their absorbance spectra cancels the signal at $250 \mathrm{~nm}$ [64]. Finally, the two most common natural chromophores (i.e., carotenoid and chlorophyll) have no specific absorbance below their Soret band, which is generally found between 300 and $450 \mathrm{~nm}$ [65]. To sum up, major interferences to sulfide quantification by this approach may solely arise from humic and fulvic acids.

Table 2 shows, as a function of the sample dilution, LOD obtained for total sulfide, sulfite, and thiosulfate, together with the effects of some of the most common interfering species found in natural waters (including humic acids and organic matter mimicked with yeast extracts as well as nitrates and $\mathrm{NaCl}$ ). It demonstrates that, once corrected, salinity is not interfering anymore for dilutions higher than 10 folds. Quantifications for weak dilutions (10 fold) also tolerate relatively high amounts of organic matter $(75 \mathrm{mg} / \mathrm{L})$ and nitrate $(200 \mu \mathrm{M})$, knowing that surface waters generally do not exceed few tens of ppm of dissolved organic matter and less than $50 \mathrm{ppm}(0.8 \mathrm{mmol} / \mathrm{L})$ of nitrates [66]. The best sensitivity of this method is thus reached with weak dilution. Nevertheless, interferences may be stronger at those weak dilutions and care should be taken to avoid precipitates that may form in the $\mathrm{pH}$-buffered measurement medium if the sample is still too concentrated (for instance, carbonate precipitates in the alkaline $\mathbf{N}$ medium). Samples that are themselves strongly buffered or display extreme pHs (i.e., $>10$ or $<4$ ) should also be diluted in order to avoid significant $\mathrm{pH}$ shifts in the measurement media. Higher levels of dilution are very interesting for samples for which high quantities of total dissolved sulfur species are expected (i.e., $>1 \mathrm{mmol} / \mathrm{L}$ ). In that case, interferences are strongly reduced and measurements will have a better accuracy even for highly polluted systems. Finally, test of interferences with sulfides, sulfites, and thiosulfates dissolved in synthetic seawater (TYA medium) or in natural subsurface water did not show any significant variations compared to calibration tests performed in UPW (Supplementary Material (available here)). This proves the total compatibility of our method with marine and terrestrial aqueous systems and more generally with a broad range of additional ions.

3.4. Method Liability. Comparison of the calculated LOD and LOQ couples shows that the method is more sensitive for sulfides compared to sulfites and thiosulfates (Tables 2 and 3). This sensitivity is better than those encountered for ion selective electrodes but still low in comparison with other techniques, for instance, the chromatographic and potentiometric ones that usually reach sensitivities higher than $1 \mu \mathrm{mol} / \mathrm{L}$ [67]. Linearity, accuracy, and precision of the method, respectively, are represented by $R^{2}$, accuracy mean, and RSD, display acceptable values (Table 3), and thus demonstrate the validity of the present quantification procedure. Measurements that have been carried out during the calibration tests with the aim to evaluate the temporal stability of the signal over 10 min show no significant variations of the recorded spectra and extracted values (data not shown). Contrary to what could have been anticipated, especially for sulfides, which are very reactive to oxygen, there was no evidence of oxidation during the measurement period whatever the dilution was.

Tables 2 and 3 show that the method is less sensitive with regard to sulfites. Nevertheless, Figure 3 also demonstrates that the signal for sulfites is increasing for high salinities. As the method is compatible with high salinities, it is therefore possible to improve its sensitivity for sulfites by increasing the ionic strength of medium $\mathbf{H}$. In parallel, a simplification of the protocol can be advantageously executed if we consider samples with low sulfite amounts $(<1 \mathrm{mmol} / \mathrm{L})$ and salinities lower or equal to seawater, which may be the 
TABLE 2: Limit of detection (LOD) obtained for total sulfide, sulfite, and thiosulfate as a function of sample dilution, salinity, and concentrations of humic acids, yeast extract, and nitrate for which first interferences with sulfur compounds occur.

\begin{tabular}{|c|c|c|c|c|c|c|c|}
\hline \multirow[b]{2}{*}{ Dilution } & \multicolumn{3}{|c|}{ LOD $(\mu \mathrm{M})$} & \multicolumn{4}{|c|}{ Interferences } \\
\hline & Total sulfide & Total sulfite & Total thiosulfate & $\begin{array}{l}\text { Humic acids } \\
\text { range }(\mathrm{mg} / \mathrm{L})\end{array}$ & $\begin{array}{l}\text { Yeast extract } \\
\text { range }(\mathrm{mg} / \mathrm{L})\end{array}$ & $\begin{array}{l}\mathrm{NaCl} \text { range }(\mathrm{g} / \mathrm{L}) / \text { without } \\
\text { salinity correction }\end{array}$ & $\mathrm{NO}_{3}$ range $(\mu \mathrm{M})$ \\
\hline X 10 & 14 & 73 & 19 & 75 & 30 & $>320 / 12$ & 200 \\
\hline X 20 & 27 & 146 & 38 & 150 & 60 & $>320 / 24$ & 400 \\
\hline X 40 & 55 & 293 & 77 & 300 & 120 & $>320 / 48$ & 800 \\
\hline
\end{tabular}

TABLE 3: Main qualitative parameters of the method obtained for the different chemical species: limits of detection and quantification (LOD and LOQ), linearity $\left(R^{2}\right)$, accuracy mean, and relative standard deviation (RSD).

\begin{tabular}{|c|c|c|c|c|c|}
\hline & LOD $(\mu \mathrm{M})$ & LOQ $(\mu \mathrm{M})$ & $R^{2}$ & Accuracy mean (\%) & RSD (\%) \\
\hline Total sulfide & 1.37 & 3.66 & 0.9997 & 0.23 & 3.45 \\
\hline Total sulfite & 7.32 & 28.75 & 0.9998 & -1.15 & 0.68 \\
\hline Total thiosulfate & 1.92 & 4.16 & 0.9992 & -3.71 & 0.61 \\
\hline
\end{tabular}

majority of surface waters. Equations (6) and (8) would thus be simplified by considering $\mathrm{S}$ and [sulfites] as null.

Several advantages arise from this method compared to other techniques. For instance, Lawrence et al. [19] observed that traditional indirect spectrophotometric methods were subjected to incertitude due to oxidative processes and that, more globally, the main hindrance of these approaches toward sulfide quantification was the lack of selectivity, especially with components such as thiocyanate, dithionite, thiols, sulfites, and thiosulfates. Even if indirect methods may be sensitive and reach sub-micromolar detection levels $[68,69]$, they strongly depend on the chemical background (namely, salinity and reactive species) of the samples and are subjected to strong interferences that require, at least, repeated and adapted calibration procedures. Comparative measurement between our method and conventional methods has been performed on one natural sample from the Dogger Aquifer (Supplementary Data, Section 5). The results showed comparable but not similar results (a difference of 20 and $42 \%$ for sulfide and sulfite contents, respectively), and the conventional method failed to assess the thiosulfate content. However, such results are difficult to interpret, not knowing if the observed differences are due to variations in the sample preservation during the procedures or due to chemical background effects.

Comparison tests between the present method and the spectrophotometric methylene blue method have also been performed on natural fresh waters spiked with sulfides (Supplementary Figure S1). The results showed a better correlation coefficient for the direct method $\left(R^{2}=0.998\right)$ than for the indirect method $\left(R^{2}=0.993\right)$. More recently, Toda et al. [70] have developed an innovative method based on $\mathrm{H}_{2} \mathrm{~S}$ vapor generation after acidification coupled to microchannel collection that was tested and adapted to onsite measurements. This technique can be considered as a direct method and appears to be very efficient $(\mathrm{LOD}=0.4 \mathrm{nM} ; \mathrm{LOQ}=1.0 \mathrm{nM})$. Nevertheless, such method works only on trace-level sulfides (1.0 to $100 \mathrm{nM})$ and is subjected to strong interferences with $\mathrm{Cu}(\mathrm{II}), \mathrm{Mn}(\mathrm{II})$, and heavy metals. For the method presented here, we first demonstrate that direct measurements were suitable regarding the risk of oxidation during handling. This is certainly due to the fact that there is neither need of reaction time nor numerous handling steps. Secondly, we show that thiocyanate and thiols could not theoretically induce interferences and that sulfites and thiosulfates were selectively and independently measured along with sulfides. Finally, performing a direct measurement provides, in addition, the opportunity to quantify polysulfides in medium $\mathbf{N}$ [47]. This would provide a very fast and detailed estimate of the sample reduction state regarding sulfur species.

\section{Conclusions}

The goal of this study was to calibrate and provide a method that allows easy to handle, fast, and reliable quantification of the main reduced sulfur species, namely, sulfides, sulfites, and thiosulfates. Measurement of total sulfide $\left(\mathrm{H}_{2} \mathrm{~S}\right.$ and $\left.\mathrm{HS}^{-}\right)$ for a large set of water qualities, especially in $\mathrm{pH}$-buffered media that contain organic matter or have high salinities, was accomplished successfully. Subtraction of second-derivative spectra acquired at different $\mathrm{pHs}$ has demonstrated its ability to overcome classical interferences induced by the presence of other reduced sulfur species together with organic and inorganic compounds commonly found in surface and subsurface waters. Together with the direct quantification of sulfites and thiosulfates, this method gives a global view of the sulfur speciation in reduced environments. Sensitivity is moderate but remains acceptable for most quantitative approaches. The development of such a methodology could lead to automatized systems, and improvements in sensitivity could be achieved by the use of other buffered media. Moreover, it should be possible to successfully develop similar approaches (i.e., subtraction of second-derivative spectra obtained at selective $\mathrm{pH}$ ) for the quantification of other $\mathrm{pH}$-sensitive chemical species.

\section{Data Availability}

The main data used to support the findings of this study are all included within the article and its Supplementary Material. The spectrophotometric raw data are available from the corresponding author upon request. 


\section{Conflicts of Interest}

The authors declare no conflicts of interest regarding the content and implications of this manuscript.

\section{Acknowledgments}

This work was supported by the Centre de Recherches sur le Stockage Géologique du $\mathrm{CO}_{2}$ (IPGP/TOTAL/SCHLUMBERGER/ADEME) and beneficiated from funds from the French Agence Nationale de la Recherche (project CO2FIX). This study contributes to the IdEx Université de Paris ANR18-IDEX-0001.

\section{Supplementary Materials}

Supplementary Material includes in particular the general procedure and recommendation to implement the present method, as well as comparisons with standardized methods and commercial kits. (Supplementary Materials)

\section{References}

[1] D. G. Maynard, Sulfur in the Environment, Marcel Dekker, New York, NY, USA, 1998.

[2] D. E. Canfield, E. Kristensen, and B. Thamdrup, Aquatic Geomicrobiology, Elsevier, San Diego, CA, USA, 1st edition, 2005.

[3] G. Leng, Q. Hu, W.-F. He et al., "A simple field method for the determination of sulfite in natural waters: based on automated dispersive liquid-liquid microextraction coupled with ultraviolet-visible spectrophotometry," Journal of Chromatography A, vol. 1584, pp. 72-79, 2019.

[4] K. Wasmund, M. Mußmann, and A. Loy, "The life sulfuric: microbial ecology of sulfur cycling in marine sediments," Environmental microbiology reports, vol. 9, no. 4, pp. 323-344, 2017.

[5] R. A. Young and M. Akhtar, Environmentally Friendly Technologies for the Pulp and Paper Industry, John Wiley \& Sons, New York, NY, USA, 1997.

[6] P. Lens, L. Hulshoff-Pol, P. Wilderer, and T. Asano, Water Recycling and Resource Recovery in Industry: Analysis, Technologies and Implementation, IWA Publishing, London, UK, 2002.

[7] A. D. Covington, Tanning Chemistry: The Science of Leather, RSC publishing, Cambridge, UK, 2011.

[8] P. L. Almeida, T. H. Figueiredo do Bonfim, F. A. S. Cunha, K. M. G. Lima, J. S. Aquino, and L. F. Almeida, "A rapid, sensitive and green analytical method for the determination of sulfite in vinegars using pararosaniline reaction with image detection," Analytical Methods, vol. 10, no. 4, pp. 448-458, 2018.

[9] P. Lens and L. Hulshoff-Pol, Environmental Technologies to Treat Sulphur Pollution: Principles and Engineering, IWA Publishing, London, UK, 2000.

[10] J. P. Amend, K. J. Edwards, and T. W. Lyons, Sulfur Biogeochemistry: Past and Present. Geological Society of America Special Paper, Vol. 379, Geological Society of America, Boulder, CO, USA, 2004.

[11] Y. Wang, F. Zan, G. Guo, T. Hao, J. Wang, and G. Chen, “A novel approach to quantifying elemental sulfur (SO) in environmental samples," Water Science and Technology, vol. 2017, no. 2, pp. 467-472, 2018.
[12] G. K. Druschel, M. A. Schoonen, D. K. Nordstrom, J. W. Ball, Y. Xu, and C. A. Cohn, "Sulfur geochemistry of hydrothermal waters in Yellowstone National Park, Wyoming, USA. III. An anion-exchange resin technique for sampling and preservation of sulfoxyanions in natural waters," Geochemical Transactions, vol. 4, no. 1, pp. 12-19, 2003.

[13] R. Gürkan, N. Altunay, and N. Gürkan, "Extraction, preconcentration and spectrophotometric determination of trace levels of thiosulfate in environmental waters," Journal of the Iranian Chemical Society, vol. 14, no. 5, pp. 1033-1049, 2017.

[14] R. Hell, C. Dahl, D. B. Knaff, and T. Leustek, Sulfur Metabolism in Phototrophic Organisms, Springer, Dordrecht, Netherlands, 2008.

[15] A. Isaac, J. Davis, C. Livingstone, A. J. Wain, and R. G. Compton, "Electroanalytical methods for the determination of sulfite in food and beverages," TrAC Trends in Analytical Chemistry, vol. 25, no. 6, pp. 589-598, 2006.

[16] R. C. Wiley, "Preservation methods for minimally processed refrigerated fruits and vegetables," in Minimally Processed Refrigerated Fruits and Vegetables, Springer, Boston, MA, USA, 2017.

[17] Z. Shareefdeen and A. Singh, Biotechnology for Odor and Air Pollution Control, Springer, Heidelberg, Germany, 2005.

[18] P. C. Ng, T. B. Hendry-Hofer, A. E Witeof et al., "Efficacy of oral administration of sodium thiosulfate and glycine in a large, swine model of oral cyanide toxicity," Annals of Emergency Medicine, 2019, In press.

[19] N. Lawrence, J. Davis, and R. G. Compton, "Analytical strategies for the detection of sulfide: a review," Talanta, vol. 52, no. 5, pp. 771-784, 2000.

[20] Y. Miura, M. Fujisaki, and P. R. Haddad, "Spectrophotometric determination of sulfide in the presence of sulfite and thiosulfate via the precipitation of bismuth(III) sulfide," Analytical Sciences, vol. 20, no. 2, pp. 363-367, 2004.

[21] A. Perry and D. Miles, "An off-the-shelf sensor for colourimetric detection of sulfide," Tetrahedron Letters, vol. 57, no. 51, pp. 5788-5793, 2016.

[22] S. Motellier, K. Gurdale, and H. Pitsch, "Sulfur speciation by capillary electrophoresis with indirect spectrophotometric detection: in search of a suitable carrier electrolyte to maximize sensitivity," Journal of Chromatography A, vol. 770, no. 1-2, pp. 311-319, 1997.

[23] Y. Miura and A. Kawaoi, "Determination of thiosulfate, thiocyanate and polythionates in a mixture by ion-pair chromatography with ultraviolet absorbance detection," Journal of Chromatography A, vol. 884, no. 1-2, pp. 81-87, 2000.

[24] S.-I. Ohira and K. Toda, "Ion chromatographic measurement of sulfide, methanethiolate, sulfite and sulfate in aqueous and air samples," Journal of Chromatography A, vol. 1121, no. 2, pp. 280-284, 2006.

[25] L. Ferrer, M. Miró, J. M. Estela, and V. Cerdà, "Analytical methodologies for reliable sulfide determinations in aqueous matrices exploiting flow-based approaches," TrAC Trends in Analytical Chemistry, vol. 26, no. 5, pp. 413-422, 2007.

[26] T. R. Crompton, Determination of Metals in Natural and Treated Water, Taylor \& Francis, London, UK, 2001.

[27] E. A. Guenther, K. S. Johnson, and K. H. Coale, "Direct ultraviolet spectrophotometric determination of total sulfide and iodide in natural waters," Analytical Chemistry, vol. 73, no. 14, pp. 3481-3487, 2001.

[28] R. E. Eckford and P. M. Fedorak, "Second derivative UV absorbance analysis to monitor nitrate-reduction by bacteria 
in most probable number determinations," Journal of $\mathrm{Mi}$ crobiological Methods, vol. 50, no. 2, pp. 141-153, 2002.

[29] T. Heitmann and C. Blodau, "Oxidation and incorporation of hydrogen sulfide by dissolved organic matter," Chemical Geology, vol. 235, no. 1-2, pp. 12-20, 2006.

[30] A. Postec, F. Lesongeur, P. Pignet, B. Ollivier, J. Querellou, and A. Godfroy, "Continuous enrichment cultures: insights into prokaryotic diversity and metabolic interactions in deepsea vent chimneys," Extremophiles, vol. 11, no. 6, pp. 747-757, 2007.

[31] J. E. Cahill, "Derivative spectroscopy: understanding its application," American Laboratory, vol. 11, pp. 79-85, 1979.

[32] A. M. C. Davies, "Back to basics: spectral pre-treamentsderivatives," European Journal of Mass Spectrometry, vol. 19, pp. 32-33, 2007.

[33] S. Motellier and M. Descostes, "Sulfur speciation and tetrathionate sulfitolysis monitoring by capillary electrophoresis," Journal of Chromatography A, vol. 907, no. 1-2, pp. 329-335, 2001.

[34] R. Steudel, "Mechanism for the formation of elemental sulfur from aqueous sulfide in chemical and microbiological desulfurization processes," Industrial \& Engineering Chemistry Research, vol. 35, no. 4, pp. 1417-1423, 1996.

[35] E. Wiberg, N. Wiberg, and A. E. Holleman, HollemanWiberg's Inorganic Chemistry, Academic Press, San Diego, CA, USA, 2001.

[36] V. K. Zinchuk and E. N. Stadnichuk, "Chemiluminescence determination of monopersulfuric acid," Journal of Analytical Chemistry, vol. 56, no. 10, pp. 918-919, 2001.

[37] G. K. Druschel, R. J. Hamers, and J. F. Banfield, "Kinetics and mechanism of polythionate oxidation to sulfate at low $\mathrm{pH}$ by $\mathrm{O}_{2}$ and $\mathrm{Fe}^{3+}, "$ Geochimica et Cosmochimica Acta, vol. 67, no. 23, pp. 4457-4469, 2003.

[38] Y. Miura, T. Maruyama, and T. Koh, "Ion chromatographic determination of L-ascorbic acid, sulfite, sulfide and thiosulfate using a cation-exchanger of low crosslinking," Analytical Sciences, vol. 11, no. 4, pp. 617-621, 1995.

[39] K. Ranguelova and R. P. Mason, "New insights into the detection of sulfur trioxide anion radical by spin trapping: radical trapping versus nucleophilic addition," Free Radical Biology and Medicine, vol. 47, no. 2, pp. 128-134, 2009.

[40] I. M. Kolthoff and P. J. Elving, Treatise on Analytical Chemistry, Interscience Encyclopedia, New York, NY, USA, 1959.

[41] K. Gupta, D. R. Roy, V. Subramanian, and P. K. Chattaraj, "Are strong Brønsted acids necessarily strong Lewis acids?," Journal of Molecular Structure: THEOCHEM, vol. 812, no. 1-3, pp. 13-24, 2007.

[42] Y. Chiang and A. J. Kresge, "Determination of the acidity constant of isothiocyanic acid in aqueous solution," Canadian Journal of Chemistry, vol. 78, no. 12, pp. 1627-1628, 2000.

[43] M. Kühn, C. Niewöhner, M. Isenbeck-Schröter, and H. D. Schulz, "Determination of major and minor constituents in anoxic thermal brines of deep sandstone aquifers in Northern Germany," Water Research, vol. 32, no. 2, pp. 265-274, 1998.

[44] T. T. Nham and A. G. Wiseman, "A new torch for analysis of samples having exceptionally high total dissolved solids by axially-viewed inductively coupled plasma optical emission spectrometry," Journal of Analytical Atomic Spectrometry, vol. 18, no. 7, pp. 790-794, 2003.

[45] I. Ali and H. Y. Aboul-Enein, Instrumental Methods in Metal Ion Speciation, CRC/Taylor \& Francis, Boca Raton, FL, USA, 2006.
[46] Y. T. Puyate and C. J. Lawrence, "Steady state solutions for chloride distribution due to wick action in concrete," Chemical Engineering Science, vol. 55, no. 16, pp. 3329-3334, 2000.

[47] W. E. Kleinjan, A. de Keizer, and A. J. H. Janssen, "Equilibrium of the reaction between dissolved sodium sulfide and biologically produced sulfur," Colloids and Surfaces B: Biointerfaces, vol. 43, no. 3-4, pp. 228-237, 2005.

[48] D. Zheng, D. Qu, X.-Q. Yang, X. Yu, H.-S. Lee, and D. Qu, "Quantitative and qualitative determination of polysulfide species in the electrolyte of a lithium-sulfur battery using HPLC ESI/MS with one-step derivatization," Advanced Energy Materials, vol. 5, no. 16, article 1401888, 2015.

[49] W. E. Kleinjan, A. de Keizer, and A. J. H. Janssen, "Kinetics of the reaction between dissolved sodium sulfide and biologically produced sulfur," Industrial \& Engineering Chemistry Research, vol. 44, no. 2, pp. 309-317, 2005.

[50] J. M. Shively, Inclusions in Prokaryotes, Springer, Heidelberg, Germany, 2006.

[51] O. Thomas and C. Burgess, UV-Visible Spectrophotometry of Water and Wastewate, Elsevier, Amsterdam, Netherlands, 2nd edition, 2017.

[52] T. R. Crompton, Determination of Anions: a Guide for the Analytical Chemist, Springer, Berlin, Germany, 1996.

[53] R. M. Onorato, D. E. Otten, and R. J. Saykally, “Adsorption of thiocyanate ions to the dodecanol/water interface characterized by UV second harmonic generation," Proceedings of the National Academy of Sciences, vol. 106, no. 36, pp. 15176-15180, 2009.

[54] T. F. Rozan and G. W. Luther, "An anion chromatography/ ultraviolet detection method to determine nitrite, nitrate, and sulfide concentrations in saline (pore) waters," Marine Chemistry, vol. 77, no. 1, pp. 1-6, 2002.

[55] Malcolm Pirnie Inc, Carollo Engineers PC, The Cadmus Group Inc, K. G. Linden, and P. Malley Jr., Ultraviolet Disinfection Guidance Manual, Diane Publishing Co, Darby, PA, USA, 2003.

[56] B. Woźniak and J. Dera, Light Absorption in Sea Water, Springer, New York, NY, USA, 2007.

[57] O. Thomas and C. Burgess, UV-Visible Spectrophotometry of Water and Wastewater, Elsevier, Amsterdam, Netherlands, 2017.

[58] S. Rajendran, B. V. Apparao, and N. Palaniswamy, "HEDP$\mathrm{Zn}^{2+}$ : a potential inhibitor system for mild steel in low chloride media," Anti-Corrosion Methods and Materials, vol. 47, no. 2, pp. 83-87, 2000.

[59] A. A. Abramov and V. M. Avdokhin, Oxidation of Sulfide Minerals in Benefication Processes, Overseas Publishers Association, Amsterdam, Netherlands, 1997.

[60] J. C. Dias, E. Suzuki, C. L. de Albuquerque, A. L. Ferreira, A. R. M. S. Brito, and L. T. Kubota, "Determination of shortchain fatty acids in dietary fiber extracts using ion-exclusion chromatography with suppressed conductivity detection," Journal of Pharmaceutical and Biomedical Analysis, vol. 49, no. 4, pp. 1128-1132, 2009.

[61] S. R. Boethling and D. Mackay, Handbook of Property Estimation Methods for Chemicals: Environmental and Health Sciences, CRC Press/Taylor \& Francis, Boca Raton, FL, USA, 2000.

[62] A. Gianguzza, E. Pelizzetti, and S. Sammartano, Chemistry of Marine Water and Sediments, Springer, Heidelberg, Germany, 2002. 
[63] M. G. Gore, Spectrophotometry \& Spectrofluorimetry, Practical Approach Series, Oxford University Press, Oxford, UK, 2000.

[64] H. Mach, C. R. Middaugh, and N. Denslow, "Determining the identity and purity of recombinant proteins by UV absorption spectroscopy," in Current Protocols in Protein Science, John Wiley \& Sons, London, UK, 2001.

[65] W. J. Hurst, Methods of Analysis for Functional Foods and Nutraceuticals, Functional Foods \& Nutraceuticals Series, CRC Press/Taylor \& Francis, Boca Raton, FL, USA, 2nd edition, 2008.

[66] M. van der Perk, "Soil and water contamination: from molecular to catchment scale," in Balkema: Proceedings and Monographs in Engineering, Water and Earth Sciences, Taylor \& Francis, Leiden, Netherlands, 2006.

[67] T. R. Crompton, Determination of Anions in Natural and Treated Waters, Spon Press, London, UK, 2002.

[68] S. E. Mylon and G. Benoit, "Subnanomolar detection of acidlabile sulfides by the classical methylene blue method coupled to HPLC," Environmental Science \& Technology, vol. 35, no. 22, pp. 4544-4548, 2001.

[69] T. V. Titova, N. S. Borisova, and N. F. Zakharchuk, "Determination of sub-micromolar amounts of sulfide by standard free anodic stripping voltammetry and anodic stripping voltammetric titration," Analytica Chimica Acta, vol. 653, no. 2, pp. 154-160, 2009.

[70] K. Toda, H. Kuwahara, and S.-I. Ohira, "On-site measurement of trace-level sulfide in natural waters by vapor generation and microchannel collection," Environmental Science \& Technology, vol. 45, no. 13, pp. 5622-5628, 2011. 

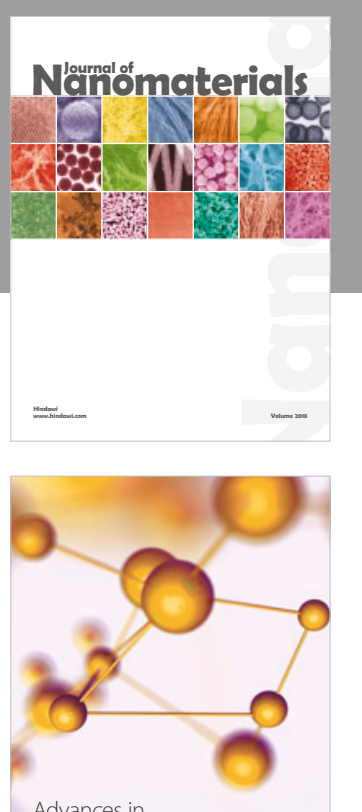

Physical Chemistry
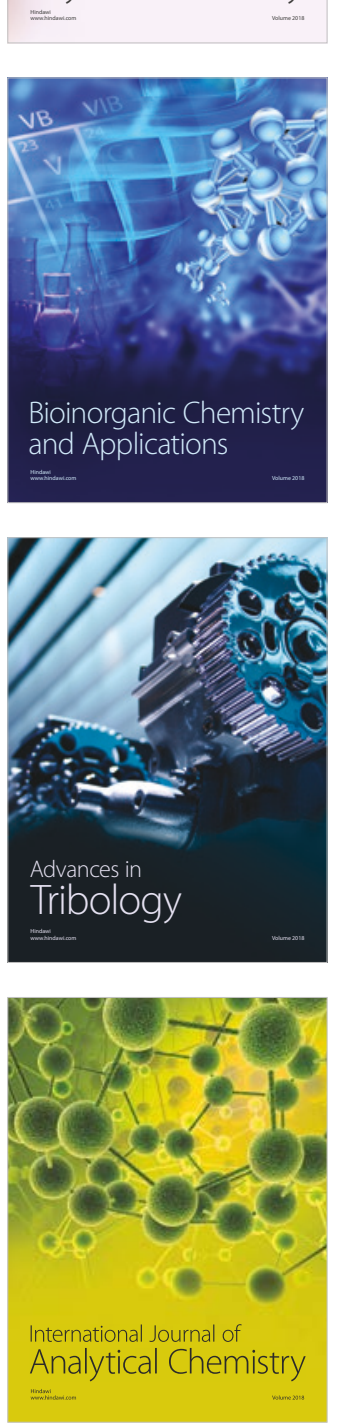

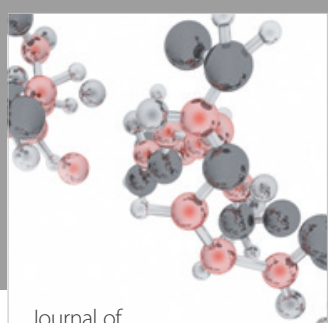

Analytical Methods

in Chemistry

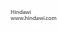

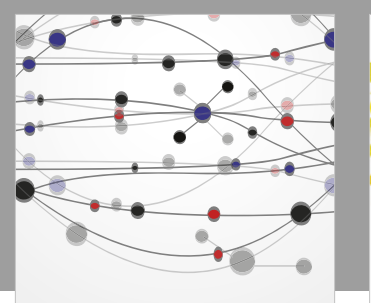

The Scientific World Journal

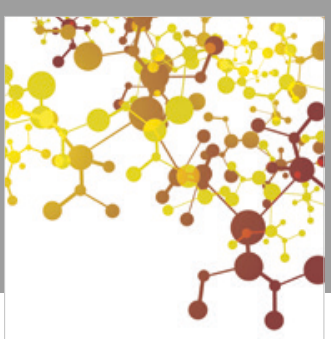

Journal of

Applied Chemistry
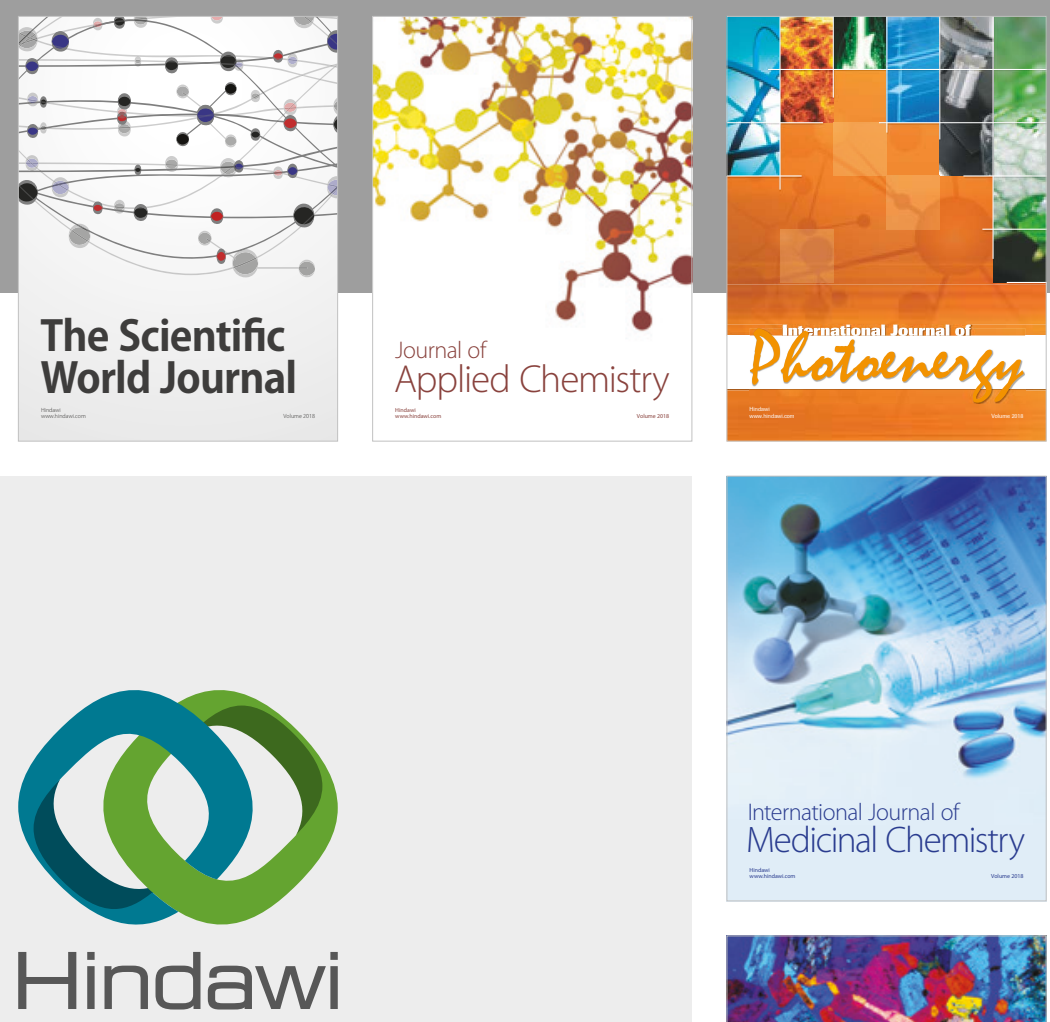

Submit your manuscripts at

www.hindawi.com
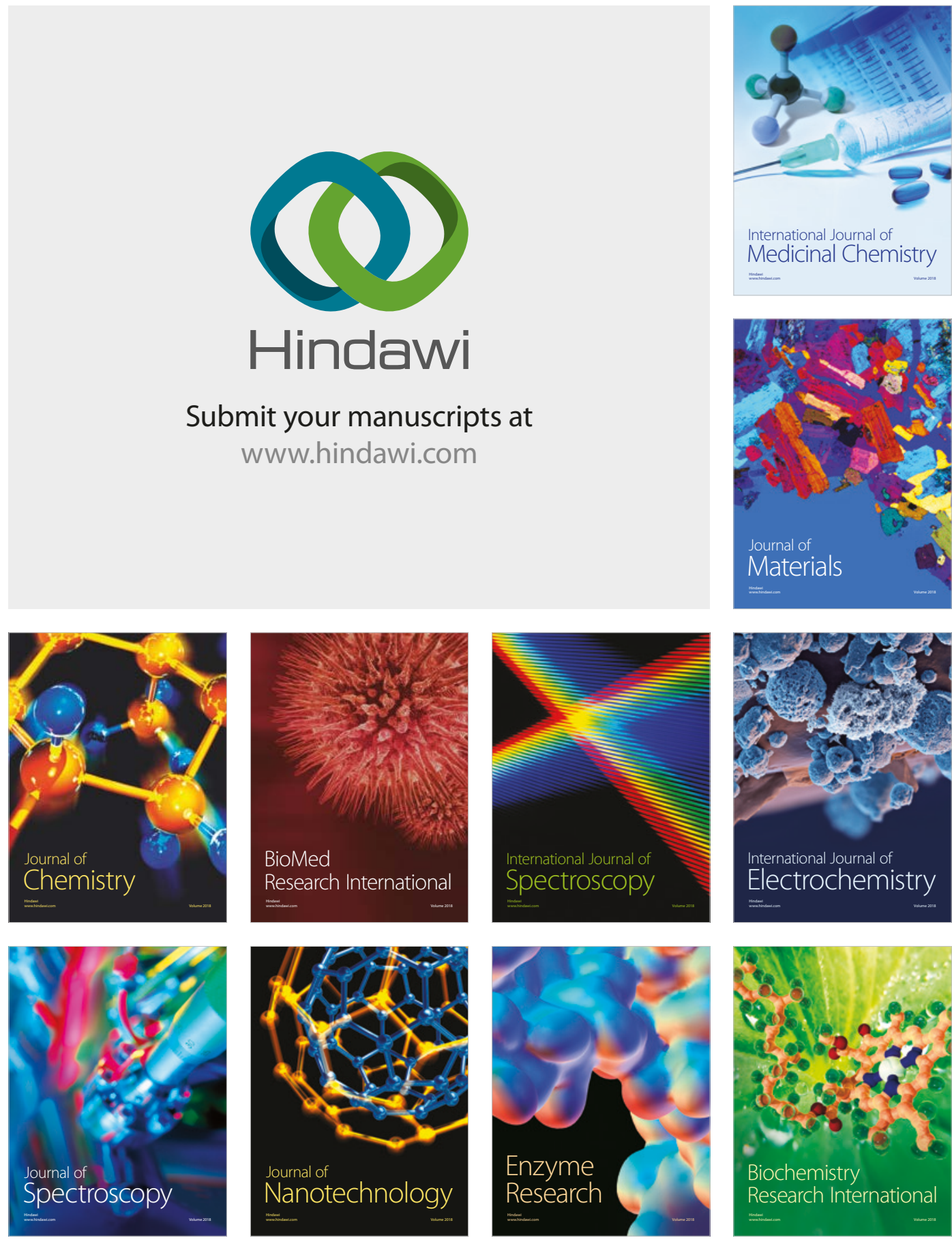
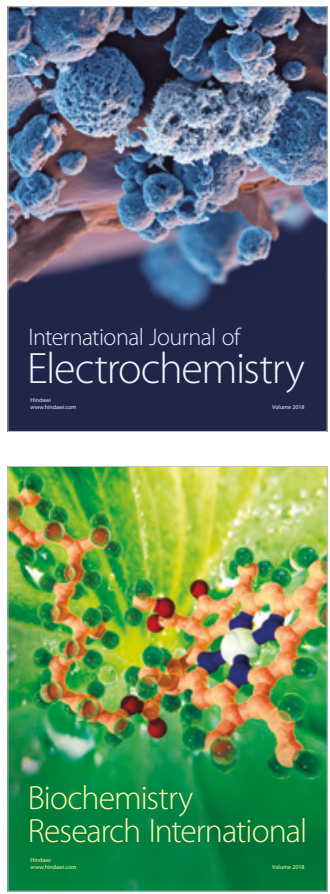